\title{
Three-dimensional alignment changes of the shoulder girdle between the supine and standing positions
}

\author{
Noboru Matsumura ${ }^{{ }^{*}}$, Yoshitake Yamada ${ }^{2 *}$, Satoshi Oki ${ }^{1}$, Yuki Yoshida ${ }^{1}$, Yoichi Yokoyama ${ }^{2}$, Minoru Yamada ${ }^{2}$, \\ Takeo Nagura ${ }^{1}$ and Masahiro Jinzaki ${ }^{2}$
}

\begin{abstract}
Background: Although humans spend most of their day in a standing or sitting position, it is difficult to accurately evaluate the alignment of the shoulder girdle during daily activity, and its alignment changes between positions. The purpose of this study was to evaluate the 3-dimensional alignment of the shoulder girdle in the supine and standing positions by computed tomography (CT) and to assess the alignment changes of the shoulder girdle between these two positions.

Methods: CT scans of both shoulders of 100 healthy volunteers were prospectively taken in both supine and standing positions on the same day. The local 3-dimensional coordinate systems of the thorax, clavicle, and scapula were defined from the specific bony landmarks, and 3-dimensional angular rotations and positions of the clavicle and scapula were calculated. Differences in rotations and positions of the clavicle and scapula were evaluated between the supine and standing positions.

Results: Compared with the supine position, the clavicle showed significantly less elevation and greater retraction, and the scapula showed significantly less upward rotation, anterior tilting, and internal rotation in the standing position. Compared with the supine position, the clavicle center was located more inferiorly, posteriorly, and laterally, and the scapula center was located more inferiorly, posteriorly, and medially in the standing position.

Conclusions: The present study showed that angular rotations and positions of the clavicle and scapula change significantly with position due to the effect of gravity.
\end{abstract}

Keywords: Shoulder girdle, Upright computed tomography, Shoulder girdle alignment, Clavicle rotation, Scapula rotation, Scapulothoracic joint

\section{Introduction}

Humans perform their activities of daily living mainly in a standing or sitting position, but it is difficult to accurately evaluate the alignment of the shoulder girdle during daily activities. Plain radiographs can be taken in an

\footnotetext{
* Correspondence: noboru18@gmail.com; yamada@rad.med.keio.ac.jp ${ }^{1}$ Department of Orthopedic Surgery, Keio University School of Medicine, 35 Shinanomachi, Shinjuku-ku, Tokyo 160-8582, Japan

${ }^{2}$ Department of Radiology, Keio University School of Medicine, 35 Shinanomachi, Shinjuku-ku, Tokyo 160-8582, Japan
}

upright position, but 3-dimensional anatomical alignment cannot be assessed on 2-dimensional projection images [1]. On the other hand, computed tomography (CT) scans have the advantage of assessing bones and joints three dimensionally, and they are now widely used to evaluate joint pathologies, but CT scans are usually taken in the supine position. Direct measurement [2] and measurement using electromagnetic tracking devices [3-6] require palpation for identification of the bony landmarks from outside of the human body, and these

(c) The Author(s). 2020 Open Access This article is licensed under a Creative Commons Attribution 4.0 International License, which permits use, sharing, adaptation, distribution and reproduction in any medium or format, as long as you give appropriate credit to the original author(s) and the source, provide a link to the Creative Commons licence, and indicate if changes were made. The images or other third party material in this article are included in the article's Creative Commons licence, unless indicated otherwise in a credit line to the material. If material is not included in the article's Creative Commons licence and your intended use is not permitted by statutory regulation or exceeds the permitted use, you will need to obtain permission directly from the copyright holder. To view a copy of this licence, visit http://creativecommons.org/licenses/by/4.0/ The Creative Commons Public Domain Dedication waiver (http://creativecommons.org/publicdomain/zero/1.0/) applies to the data made available in this article, unless otherwise stated in a credit line to the data. 
measurement methods cannot exclude the effect of the skin artifact. Though the anatomical alignment of the shoulder girdle can change with body position, its alignment changes between positions have not been evaluated.

A newly developed upright CT scanner, whose transverse 320 row-detector gantry includes a stand supporting the rotary section on either side with a linear motion rail and ball screw to move the scanner up and down, enables whole-torso cross-sectional scanning with a 3dimensional acquisition in the standing position [7] and evaluation of the effect of gravity on the human body [8]. The purpose of this study was to evaluate the 3dimensional alignment of the shoulder girdle in the supine position using a conventional CT scanner and in the standing position using a newly developed upright CT scanner and to assess the alignment changes of the girdle between these two positions. We hypothesized that angular rotations and positions of the shoulder girdle differ between the supine and standing positions due to the effect of gravity.

\section{Methods}

\section{Participants}

This study was approved by the Institutional Review Board of Keio University School of Medicine (reference study number 20160384), and written, informed consent was obtained from all participants. The inclusion criteria for this study were healthy volunteers without any past medical history, age ranging from 30 to 60 years, and who showed complete understanding of the details of their involvement and provided their informed consent to participate in this study. The exclusion criteria were shoulders with obvious degenerative changes in the sternoclavicular, acromioclavicular, and glenohumeral joints, and spinal scoliosis with Cobb's angle greater than $10^{\circ}$ [9] on the CT scans obtained. A total of 106 healthy volunteers were prospectively recruited by a volunteer recruitment company. Of these, 6 participants were excluded because CT showed asymptomatic spinal scoliosis. Thus, 200 shoulders from 100 healthy volunteers (60 females and 40 males) were included in the analysis. The participants' mean ( \pm standard deviation) age, height, and weight were $43.2 \pm 8.0$ years (range, 30-59 years), $171.4 \pm 6.4 \mathrm{~cm}$ (range, $159.1-187.5 \mathrm{~cm}$ ), and 68.1 $\pm 9.6 \mathrm{~kg}$ (range, $47.4-88.2 \mathrm{~kg}$ ) in males, and $44.9 \pm 8.5$ years (range, $30-60$ years), $157.0 \pm 5.2 \mathrm{~cm}$ (range, 147.7$170.7 \mathrm{~cm}$ ), and $53.9 \pm 8.0 \mathrm{~kg}$ (range, $37.8-77.5 \mathrm{~kg}$ ) in females, respectively.

CT scans of both shoulders of the volunteers were taken in the supine position using a conventional 320detector row CT scanner (Aquilion ONE; Canon Medical Systems Corporation, Otawara, Japan) and in the standing position using an upright 320-detector row CT scanner (prototype TSX-401R; Canon Medical Systems Corporation) on the same day. During CT scanning in the supine position, the volunteers were placed on the floor of the CT scanner with their arms at their sides (Fig. 1a). During upright CT scanning, the volunteers stood in the transverse gantry with the shoulders adducted and the arms held in the neutral position, and a support pole was placed behind them to stabilize the back (Fig. 1b). CT scans of both shoulders in the standing position were acquired during up-and-down movements of the transverse gantry [7]. The total effective dose of radiation exposure was tracked during all CT scanning and was controlled to not exceed $30 \mathrm{mSv}$. The image data were extracted in the obtained Digital Imaging and Communication in Medicine data format.

\section{Measurements of shoulder girdle alignment}

Using OsiriX MD 11.0.0 software (Pixmeo, Geneva, Switzerland), the specific bony landmarks were identified on both supine and standing CT scans of 200 shoulders. According to the International Society of Biomechanics standardization proposal for the upper extremity, the 7th cervical vertebra (C7), 8th thoracic vertebra (T8), sternal notch (incisura jugularis; IJ), and xiphoid process (processus xiphoideus; PX) were digitized as the thoracic landmarks [10]. The sternoclavicular joint, which was defined as the most ventral point on the proximal end of the clavicle (SC), and the acromioclavicular joint, which was defined as the most dorsal point on the distal end of the clavicle $(\mathrm{AC})$, were used for the clavicle, whereas the root of the scapular spine (trigonum spinae scapulae; $\mathrm{TS}$ ), inferior angle (angulus inferior; AI), and posterolateral edge of the acromion (angulus acromialis; AA) were used for the scapula.

The local 3-dimensional coordinate systems of the thorax, clavicle, and scapula were defined from the specific bony landmarks on both supine and standing CT scans. In the thoracic coordinate system, the $\mathrm{Y}$-axis was defined as the line connecting the midpoint between PX and $\mathrm{T} 8$ and the midpoint between $\mathrm{IJ}$ and $\mathrm{C} 7$, pointing upward; the $\mathrm{Z}$-axis was the line perpendicular to the plane formed by IJ, C7, and the midpoint between PX and T8, pointing lateral; and the $\mathrm{X}$-axis was the common line perpendicular to the $\mathrm{Z}$ - and $\mathrm{Y}$-axes, pointing forward. The origin of the thoracic coordinate system was coincident with the sternal notch. In the clavicular coordinate system, the Z-axis was defined as the line connecting $\mathrm{SC}$ and $\mathrm{AC}$, pointing lateral; the $\mathrm{X}$-axis was the line perpendicular to the clavicular Z-axis and the thoracic $\mathrm{Y}$-axis, pointing forward; and the $\mathrm{Y}$-axis was the common line perpendicular to the $\mathrm{X}$ - and $\mathrm{Z}$-axes, pointing upward (Fig. 2a). In the scapular coordinate system, the Z-axis was defined as the line connecting TS and $\mathrm{AA}$, pointing lateral; the $\mathrm{X}$-axis was the line 

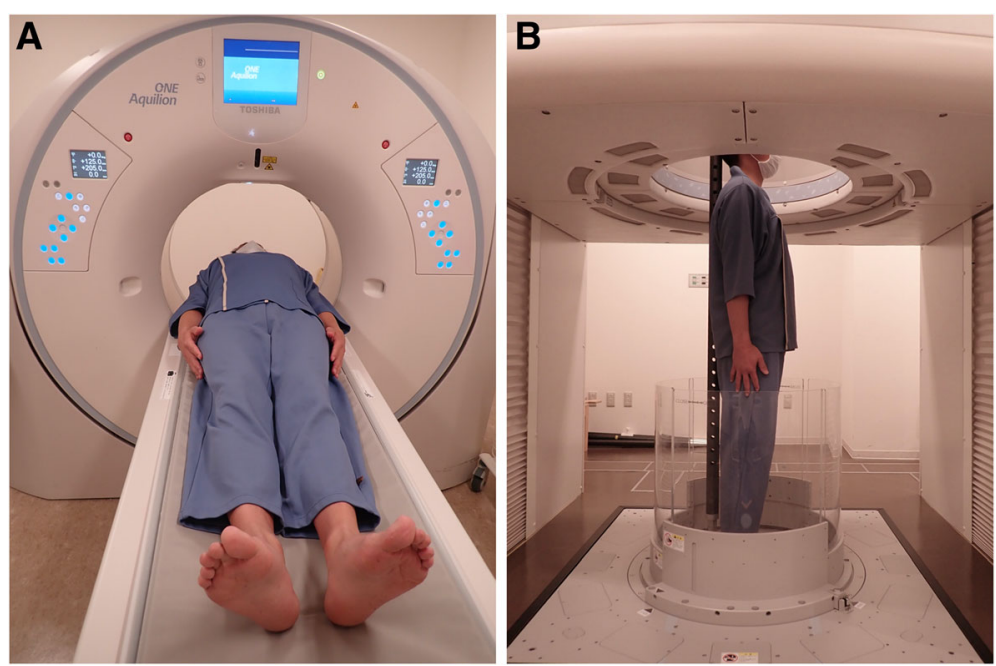

Fig. 1 Computed tomography scanning in the supine and standing positions. a CT scans of both shoulders of the volunteers are taken in the supine position using a conventional 320-detector row CT scanner. b CT scans are taken in the standing position using an upright CT scanner, which has a transverse 320 row-detector gantry. A support pole lightly supports the back of the volunteer, and up-and-down movements of the transverse gantry enable cross-sectional scanning in the standing position

perpendicular to the plane formed by AI, AA, and TS, pointing forward; and the $\mathrm{Y}$-axis was the common line perpendicular to the $\mathrm{X}$ - and $\mathrm{Z}$-axes, pointing upward (Fig. 2b). The angular rotation of the clavicle and scapula were calculated using Cardan or Euler angles relative to the thorax following recommendations of the International Society of Biomechanics [10]. Clavicular rotation with respect to the thorax was described as clavicular elevation/depression and retraction/protraction, and scapular rotation with respect to the thorax was described as scapular upward/downward rotation, anterior/posterior tilting, and internal/external rotation [5]. Clavicular axial rotation is usually defined as $0^{\circ}$ on the thoracic coordinate systems and could not be evaluated in this study. To assess the movements of the clavicle and the scapula, the 3-dimensional position of the

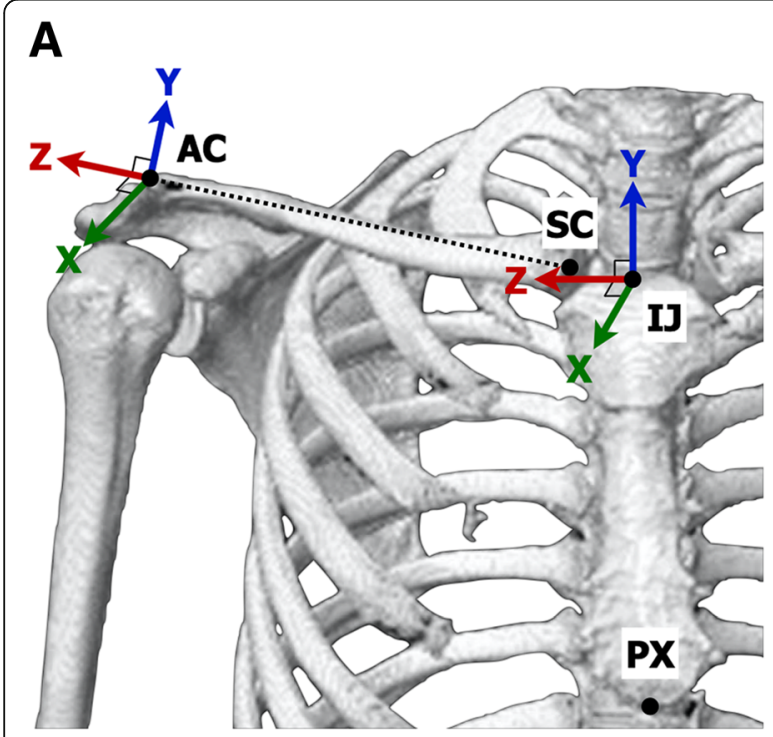

B

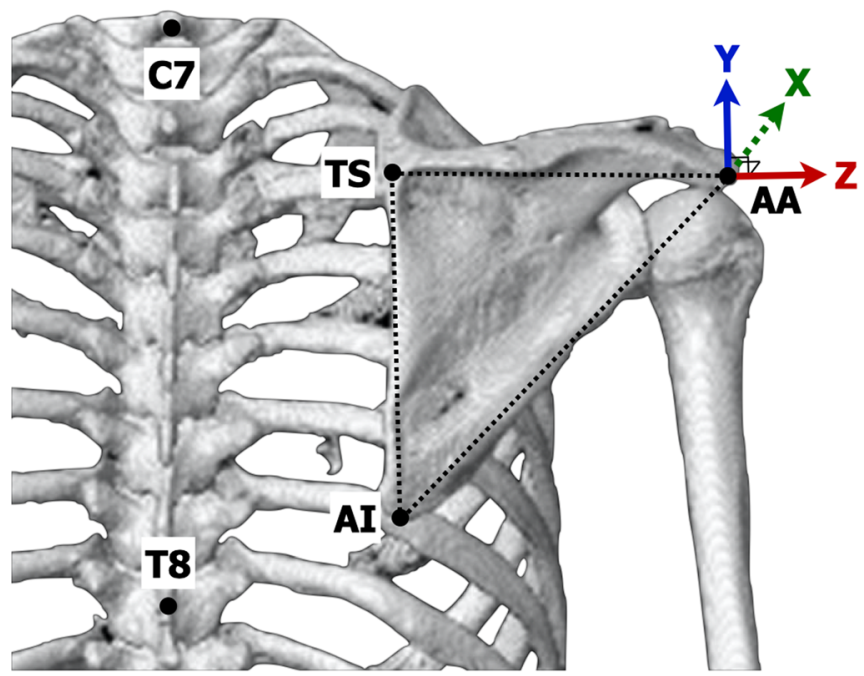

Fig. 2 The local 3-dimensional coordinate systems of the thorax, clavicle, and scapula. a The thorax and clavicular coordinate systems are defined from the specific bony landmarks on CT scans, and the angular rotation of the clavicle relative to the thorax is calculated. IJ, sternal notch; PX, xiphoid process; SC, sternoclavicular joint; AC, acromioclavicular joint. $\mathbf{b}$ The scapular coordinate systems are defined from the specific bony landmarks of the scapula, and the angular rotation of the scapula relative to the thorax is calculated. C7, 7th cervical vertebra; T8, 8th thoracic vertebra; TS, root of the scapular spine; Al, inferior angle of the scapula; AA, posterolateral edge of the acromion 
clavicle center, which was defined as the midpoint between the acromioclavicular joint and the sternoclavicular joint, and that of the scapula center, which was defined as the center of gravity of the triangle consisting of the 3 bony landmarks of the scapula, were also calculated in superior/inferior, anterior/posterior, and medial/ lateral directions on the thorax coordinate system.

\section{Statistical analysis}

Statistical analyses were performed using IBM SPSS Statistics 25.0.0.0 software (IBM Corp., Armonk, NY, USA). Intrarater and interrater reliabilities were first evaluated in 20 randomly selected cases using intraclass correlation coefficients (ICCs). Repeated measurements by 1 observer with a 3-month interval (ICC model 1, 1) and blinded measurements by 2 observers (ICC model 2, 1) were performed. After determining intra- and interrater reliabilities, analyses were performed for all shoulders by 1 observer.

The values of the angular rotations of the clavicle and the scapula and of the positions of the clavicle center and the scapula center in standing CT scans were compared with those in supine CT scans using Wilcoxon signed-rank tests. Sex differences in angular rotations and positions of the clavicle and the scapula were also assessed using Mann-Whitney $U$ tests. The significance level was set at 0.05 for all analyses.

\section{Results}

Intra- and interrater reliabilities exceeded 0.8 for angular rotations (Table 1) and 0.9 for positions (Table 2) for all measurements and were regarded as excellent. Anatomical alignment of the shoulder girdle changed significantly between the supine and standing positions. In the supine position, the average clavicular angular rotation was $14^{\circ} \pm 4^{\circ}$ in elevation and $20^{\circ} \pm 5^{\circ}$ in retraction. Compared with the supine position, the clavicle showed significantly less elevation $\left(7^{\circ} \pm 4^{\circ}, P<.001\right)$ and greater retraction $\left(23^{\circ} \pm 5^{\circ}, P<.001\right)$ in the standing position (Fig. 3a). In the supine position, the average scapular angular rotation was $16^{\circ} \pm 4^{\circ}$ in upward rotation, $12^{\circ} \pm 5^{\circ}$ in anterior tilting, and $32^{\circ} \pm 5^{\circ}$ in internal rotation. The scapula had significantly less upward rotation $\left(10^{\circ} \pm 5^{\circ}\right.$, $P<.001)$, anterior tilting $\left(8^{\circ} \pm 5^{\circ}, P<.001\right)$, and internal rotation $\left(30 \pm 6^{\circ}, P<.001\right)$ in the standing position than in the supine position (Fig. 3b). Males had significantly greater clavicular elevation and scapular anterior tilting than females $(P \leq .014)$. On the other hand, females showed greater scapular upward rotation and scapular internal rotation, and the differences became significant in scapular upward rotation in the supine position $(P=$ $0.028)$ and scapular internal rotation in the standing position $(P=.022)$ (Table 1$)$.

In the supine position, the clavicle center was located at $23.3 \pm 6.0 \mathrm{~mm}$ superior, $19.9 \pm 6.5 \mathrm{~mm}$ posterior, and $85.4 \pm 6.5 \mathrm{~mm}$ lateral to the sternal notch. Compared with the supine position, the clavicle center was located more inferiorly $(14.2 \pm 6.1 \mathrm{~mm}$ superior, $P<.001)$, posteriorly $(24.0 \pm 7.7 \mathrm{~mm}$ posterior, $P<.001)$, and laterally $(86.7 \pm 7.5 \mathrm{~mm}$ lateral, $P<.001)$ in the standing position (Fig. 4a). The scapula center was located at $4.2 \pm 10.8$ $\mathrm{mm}$ inferior, $74.2 \pm 10.7 \mathrm{~mm}$ posterior, and $143.2 \pm 10.6$ $\mathrm{mm}$ lateral to the sternal notch in the supine position. Compared with the supine position, the scapula center was located more inferiorly $(22.0 \pm 10.6 \mathrm{~mm}$ inferior, $P<$ $.001)$, posteriorly $(82.0 \pm 13.5 \mathrm{~mm}$ posterior, $P<.001)$, and medially $(138.5 \pm 11.0 \mathrm{~mm}$ lateral, $P<.001)$ in the standing position (Fig. 4b). All of the values of the 3dimensional positions of the clavicle center and the scapula center showed sex differences. The clavicle was

Table 1 Three-dimensional angular rotations of the clavicle and scapula

\begin{tabular}{|c|c|c|c|c|c|c|c|c|}
\hline & & & \multicolumn{3}{|c|}{ Mean \pm SD } & \multirow{2}{*}{$\begin{array}{l}\text { Sex difference } \\
P \text { value }\end{array}$} & \multicolumn{2}{|l|}{ ICC (95\% Cl) } \\
\hline & & & Total & Male & Female & & Intrarater & Interrater \\
\hline \multirow[t]{5}{*}{ Supine position } & Clavicle & Elevation $\left(^{\circ}\right)$ & $14 \pm 4$ & $15 \pm 4$ & $14 \pm 4$ & $.014^{*}$ & $0.998(0.995-0.999)$ & $0.989(0.962-0.996)$ \\
\hline & & Retraction $\left(^{\circ}\right)$ & $20 \pm 5$ & $20 \pm 5$ & $20 \pm 4$ & .494 & $0.991(0.978-0.996)$ & $0.894(0.562-0.965)$ \\
\hline & Scapula & Upward rotation $\left(^{\circ}\right)$ & $16 \pm 4$ & $15 \pm 4$ & $17 \pm 4$ & $.028^{*}$ & $0.986(0.966-0.994)$ & $0.990(0.903-0.997)$ \\
\hline & & Anterior tilting $\left(^{\circ}\right)$ & $12 \pm 5$ & $13 \pm 6$ & $11 \pm 5$ & $.015^{*}$ & $0.994(0.986-0.998)$ & 0.998 (0.994-0.999) \\
\hline & & Internal rotation $\left(^{\circ}\right)$ & $32 \pm 5$ & $31 \pm 5$ & $32 \pm 5$ & .060 & $0.879(0.724-0.950)$ & $0.827(0.617-0.928)$ \\
\hline \multirow[t]{5}{*}{ Standing position } & Clavicle & Elevation $\left(^{\circ}\right)$ & $7 \pm 4$ & $8 \pm 4$ & $6 \pm 4$ & $<.001^{* * *}$ & $0.994(0.984-0.997)$ & $0.940(0.856-0.976)$ \\
\hline & & Retraction $\left(^{\circ}\right)$ & $23 \pm 5$ & $23 \pm 6$ & $23 \pm 5$ & .840 & 0.995 (0.988-0.998) & $0.968(0.752-0.991)$ \\
\hline & Scapula & Upward rotation $\left({ }^{\circ}\right)$ & $10 \pm 5$ & $10 \pm 5$ & $11 \pm 4$ & .052 & $0.980(0.952-0.992)$ & $0.952(0.875-0.981)$ \\
\hline & & Anterior tilting $\left(^{\circ}\right)$ & $8 \pm 5$ & $10 \pm 5$ & $7 \pm 5$ & $<.001^{* * *}$ & $0.999(0.997-1.000)$ & $0.958(0.899-0.983)$ \\
\hline & & Internal rotation $\left(^{\circ}\right)$ & $30 \pm 6$ & $29 \pm 6$ & $31 \pm 6$ & $.022^{*}$ & $0.914(0.800-0.965)$ & $0.936(0.847-0.974)$ \\
\hline
\end{tabular}

$S D$, standard deviation; ICC, intraclass correlation coefficient; $C l$, confidence interval

${ }^{*} P<.05$

${ }^{* *} P<.01$

*** $P<.001$ 
Table 2 Three-dimensional positions of the clavicle center and scapula center

\begin{tabular}{|c|c|c|c|c|c|c|c|c|}
\hline & & & \multicolumn{3}{|l|}{ Mean \pm SD } & \multirow{2}{*}{$\begin{array}{l}\text { Sex difference } \\
P \text { value }\end{array}$} & \multicolumn{2}{|l|}{ ICC (95\% CI) } \\
\hline & & & Total & Male & Female & & Intrarater & Interrater \\
\hline \multirow[t]{6}{*}{ Supine position } & Clavicle & Inferior (mm) & $-23.3 \pm 6.0$ & $-26.0 \pm 5.6$ & $-21.4 \pm 5.5$ & $.026^{*}$ & 0.996 (0.989-0.998) & $0.908(0.718-0.966)$ \\
\hline & & Posterior (mm) & $20.0 \pm 6.5$ & $21.5 \pm 7.1$ & $18.9 \pm 5.8$ & $<.001^{* * *}$ & $0.998(0.994-0.999)$ & $0.986(0.966-0.995)$ \\
\hline & & Lateral (mm) & $85.4 \pm 6.5$ & $91.3 \pm 4.6$ & $81.5 \pm 4.4$ & $<.001^{* * *}$ & 0.999 (0.999-1.000) & $0.987(0.966-0.995)$ \\
\hline & Scapula & Inferior (mm) & $4.4 \pm 10.8$ & $1.9 \pm 11.4$ & $6.0 \pm 10.0$ & $<.001^{* * *}$ & $0.977(0.944-0.991)$ & $0.978(0.945-0.991)$ \\
\hline & & Posterior (mm) & $74.2 \pm 10.7$ & $81.4 \pm 9.8$ & $69.4 \pm 8.3$ & $.016^{*}$ & 0.996 (0.989-0.998) & $0.997(0.992-0.999)$ \\
\hline & & Lateral (mm) & $143.2 \pm 10.6$ & $153.4 \pm 7.0$ & $136.4 \pm 6.2$ & $<.001^{* * *}$ & $0.998(0.994-0.999)$ & $0.995(0.872-0.999)$ \\
\hline \multirow[t]{6}{*}{ Standing position } & Clavicle & Inferior (mm) & $-14.2 \pm 6.1$ & $-16.9 \pm 5.8$ & $-12.5 \pm 5.6$ & $.004^{* *}$ & 0.997 (0.993-0.999) & $0.978(0.707-0.994)$ \\
\hline & & Posterior (mm) & $24.0 \pm 7.7$ & $26.1 \pm 9.2$ & $22.6 \pm 6.3$ & $<.001^{* * *}$ & $0.996(0.990-0.998)$ & $0.967(0.918-0.987)$ \\
\hline & & Lateral (mm) & $86.7 \pm 7.5$ & $93.1 \pm 4.6$ & $82.4 \pm 5.8$ & $<.001^{* * *}$ & 0.997 (0.992-0.999) & $0.958(0.897-0.983)$ \\
\hline & Scapula & Inferior (mm) & $22.0 \pm 10.6$ & $19.2 \pm 11.3$ & $23.8 \pm 9.8$ & $<.001^{* * *}$ & $0.986(0.967-0.995)$ & $0.994(0.984-0.998)$ \\
\hline & & Posterior (mm) & $82.0 \pm 13.5$ & $90.9 \pm 13.6$ & $76.1 \pm 9.8$ & $.009^{* *}$ & 0.989 (0.974-0.996) & $0.995(0.988-0.998)$ \\
\hline & & Lateral (mm) & $138.5 \pm 11.0$ & $148.7 \pm 7.7$ & $131.7 \pm 6.8$ & $<.001 * * *$ & $0.998(0.995-0.999)$ & $0.991(0.908-0.998)$ \\
\hline
\end{tabular}

$S D$, standard deviation; ICC, intraclass correlation coefficient; $C l$, confidence interval

${ }^{*} P<.05$

**P $<.01$

***P $<<.001$

located more superiorly, posteriorly, and laterally $(P \leq$ .026), and the scapula was located more superiorly, posteriorly, and laterally $(P \leq .016)$ in males than in females (Table 2).

\section{Discussion}

Although humans spend most of their day in a standing or sitting position, little is known about the effect of gravity on the anatomical structures of the human body. This study evaluated the anatomical alignment of the shoulder girdle in the standing position using a newly developed upright CT scanning system, which had been validated to be comparable with conventional supine $\mathrm{CT}$ scans [7]. The present results showed that the anatomical alignment of the shoulder girdle changed significantly between the supine position and the standing position.

The present study is the first to report the normal values of the anatomical alignment of the clavicle and the scapula in the standing position using CT scans, and the values of our results were consistent with those of the past reports using electromagnetic tracking systems [3-6]. The shoulder girdle consists of the thorax, clavicle, scapula, and humerus. The scapula, in particular, is
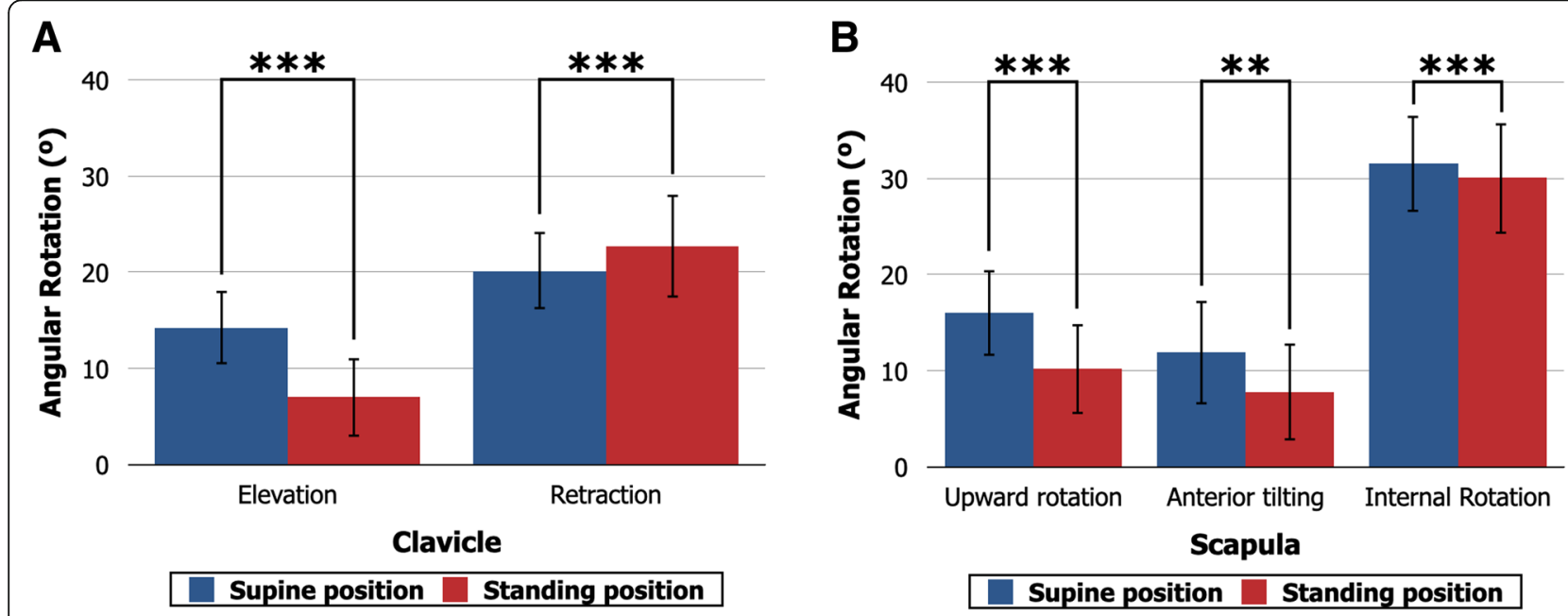

Fig. 3 Three-dimensional angular rotations of the clavicle and scapula in the supine and standing positions. a Three-dimensional angular rotations of the clavicle. Compared with the supine position, the clavicle shows significantly less elevation and greater retraction in the standing position. ${ }^{* *} P<.001$. b Three-dimensional angular rotations of the scapula. Compared with the supine position, the scapula shows less upward rotation, anterior tilting, and internal rotation in the standing position. ${ }^{* *} P<.01 .{ }^{* *} P<.001$ 

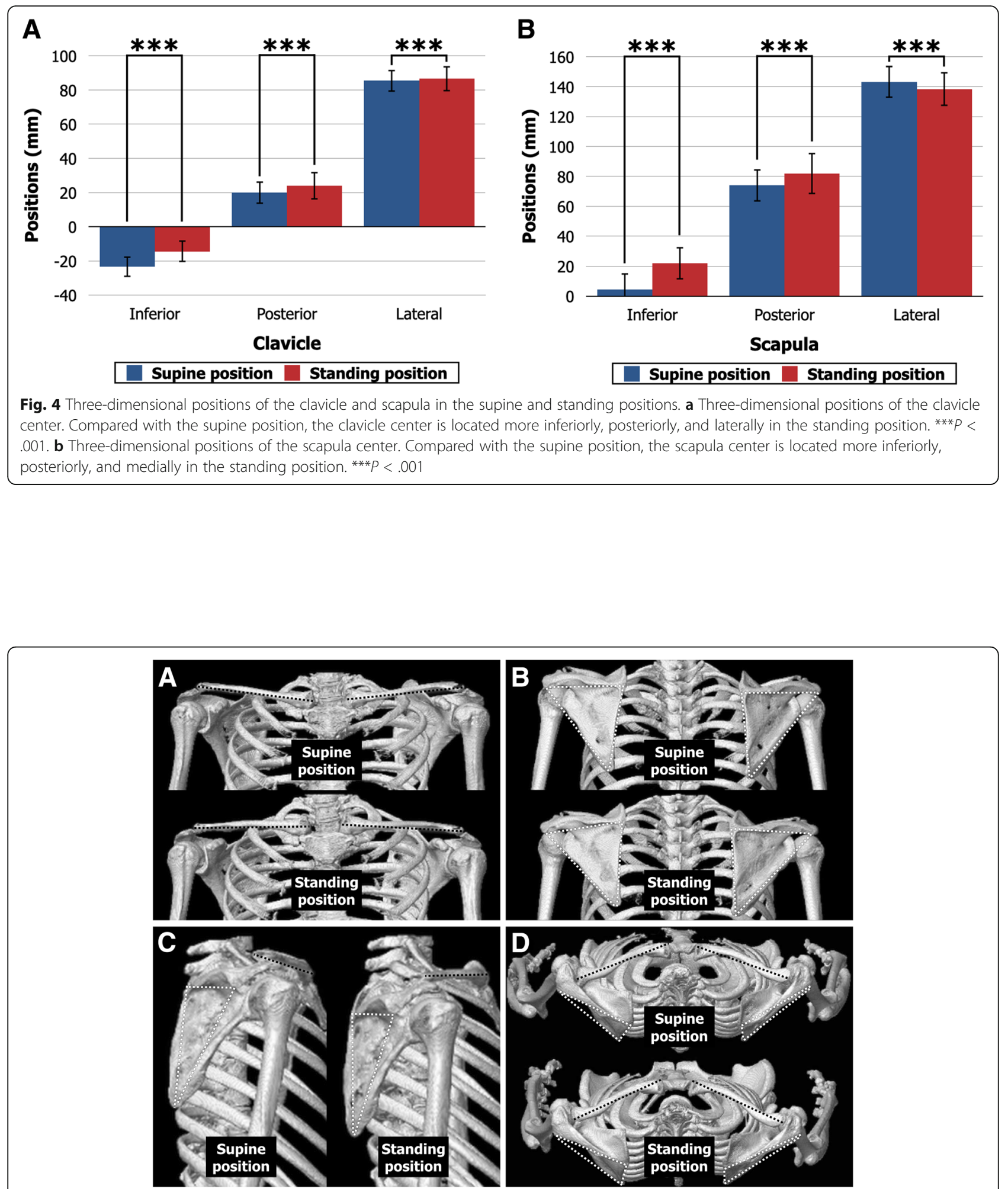

Fig. 5 Three-dimensional CT scans in the supine and standing positions. a Anterior view. Compared with the supine position, elevation of the clavicle (black dotted lines) decreases in the standing position due to the effect of gravity. b Posterior view. Compared with the supine position, upward rotation of the scapula (surrounded by white dotted lines) decreases in the standing position due to the effect of gravity. $\mathbf{c}$ Lateral view. Compared with the supine position, the scapula (surrounded by white dotted lines) is located inferiorly and tilts posteriorly in the standing position. $\mathbf{d}$ Superior view. Compared with the supine position, the clavicle (black dotted lines) shows greater retraction, and the scapula (surrounded by white dotted lines) is located medially and rotates externally in the standing position 
surrounded by the trapezius, rhomboid, levator scapulae, serratus anterior, deltoid, biceps, triceps, and rotator cuff muscles, [11] and scapular malposition and dyskinesis have been reported to occur with various shoulder pathologies [12-15]. Scapular posture is reported to differ between the dominant and nondominant shoulders in overhead throwing athletes $[4,6]$ and between throwing athletes and non-athletes, [3,6] and the SICK (scapular malposition, inferior medial border prominence, coracoid pain and malposition, and dyskinesis of scapular movement) scapula syndrome is thought to be a cause of shoulder pain in the throwing athlete who presents with dead arm complaints [14]. Scapular malposition and dyskinesis are now judged by visual appearance, [13-15] but objective and quantitative assessment is desirable for precise assessment and adequate physical rehabilitation. Since the alignment of the clavicle and the scapula differs significantly between human positions, we believe that detailed assessment of the shoulder girdle in an upright position would help clarify the complex mechanisms and various pathologies of the shoulder girdle in future studies.

With the effect of gravity, the clavicle and the scapula appeared to move and rotate downwardly in the standing position compared with the supine position (Fig. 5a and b). The weight of the unilateral upper extremity corresponds to $4 \%$ to $5 \%$ of total body weight $[16,17]$. Then, the inferior movement of the scapula along with the thoracic wall, which is a conical shape, is supposed to move and tilt the scapula posteriorly (Fig. 5c). We had presumed that the scapular body is close to parallel to the floor when facing upward, and the scapula has less internal rotation in the supine position compared with the standing position. Contrary to our expectation, however, the scapula rotated externally in the standing position, probably due to the shape of the thorax. In addition, the clavicular retraction was likely to increase in the standing position following the posterior translation of the acromion (Fig. 5d).

In the present study, angular rotations and positions of the shoulder girdle showed small but significant differences between males and females. Differences in body size, $[18,19]$ bony shape, [20], or muscles [21] between sexes are thought to cause a difference in the shoulder girdle. Since males have a larger body size than females, [18] it is natural that the distance between the sternal notch and each bone center is greater in males than in females. Nevertheless, the distance to the scapula center in the inferior direction was significantly greater in females than males, both in the supine and standing positions. There are sex differences in skeletal muscle fibertype composition and function [21]. We assumed that the muscles anchoring the scapula to the thorax, such as trapezius, levator scapulae, and rhomboids [11], are stronger in males than females and support the scapula upwardly.

The present study had several limitations. First, the participants were healthy volunteers without any shoulder symptoms. In cases with shoulder pathology, which often occurs with dyskinesis of the shoulder girdle [1315], alignment changes might differ from the present results. Furthermore, the angle differences found between the supine and standing positions were less than $10^{\circ}$ and relatively small, though the present study showed alignment changes between positions. Thus, the clinical significance of the alignment changes of the shoulder girdle remained unclear. Assessment in the supine position could be another limitation of this study. For the safety of the patients, the floor of the conventional CT scanner is rounded. Although it was confirmed that no shoulders were pushed up by the floor of the CT scanner in the present study, the results for shoulder girdle alignment might differ from that in the natural supine position on a floor.

\section{Conclusion}

Three-dimensional alignment of the shoulder girdle was evaluated in the supine and standing positions using CT scans. Due to the effect of gravity, 3-dimensional angular rotations and positions of the clavicle and scapula change significantly with position.

\section{Abbreviations \\ CT: Computed tomography; C7: The 7th cervical vertebra; T8: 8th thoracic vertebra; IJ: Sternal notch; PX: Xiphoid process; SC: The sternoclavicular joint; AC: The acromioclavicular joint; TS: The root of the scapular spine; Al: Inferior angle of the scapula; AA: Posterolateral edge of the acromion; ICC: Intraclass correlation coefficient; SICK: Scapular malposition, inferior medial border prominence, coracoid pain and malposition, and dyskinesis of scapular movement}

\section{Acknowledgements}

None

Authors' contributions

Noboru Matsumura and Yoshitake Yamada conceived of the study, analyzed the collected data, and drafted the manuscript. Yoichi Yokoyama and Minoru Yamada recruited subjects and assembled the database. Satoshi Oki and Yuki Yoshida analyzed the collected data. Takeo Nagura and Masahiro Jinzaki supervised the writing of the paper and gave final approval. All authors read and approved the final manuscript.

\section{Funding}

This study was supported by the Japan Society for the Promotion of Science (JSPS) KAKENHI (grant number JP17H04266, JP17K16482, and JP20K08056), Uehara Memorial Foundation, and Canon Medical Systems (Otawara, Japan).

\section{Availability of data and materials}

The datasets used and/or analyzed during the current study are available from the corresponding author on reasonable request.

\section{Ethics approval and consent to participate}

This study was approved by the Institutional Review Board of Keio University School of Medicine (Reference study number 20160384), and written, consent was obtained from all participants. 


\section{Consent for publication}

Not applicable.

\section{Competing interests}

Masahiro Jinzaki has received a grant from Canon Medical Systems. However, Canon Medical Systems was not involved in the design and conduct of the study; in the collection, analysis, and interpretation of the data; or in the preparation, review, and approval of the manuscript. The remaining authors have no conflicts of interest to declare.

Received: 8 May 2020 Accepted: 31 August 2020

Published online: 15 September 2020

\section{References}

1. de Groot JH. The scapulo-humeral rhythm: effects of 2-D roentgen projection. Clin Biomech (Bristol, Avon). 1999;14:63-8.

2. Sobush DC, Simoneau GG, Dietz KE, Levene JA, Grossman RE, Smith WB. The lennie test for measuring scapular position in healthy young adult females: a reliability and validity study. J Orthop Sports Phys Ther. 1996;23: 39-50.

3. Myers JB, Laudner KG, Pasquale MR, Bradley JP, Lephart SM. Scapular position and orientation in throwing athletes. Am J Sports Med. 2005;33: 263-71.

4. Oyama S, Myers JB, Wassinger CA, Daniel Ricci R, Lephart SM. Asymmetric resting scapular posture in healthy overhead athletes. J Athl Train. 2008;43: $565-70$.

5. Ludewig PM, Phadke V, Braman JP, Hassett DR, Cieminski CJ, LaPrade RF. Motion of the shoulder complex during multiplanar humeral elevation. J Bone Joint Surg Am. 2009;91:378-89.

6. Ribeiro A, Pascoal AG. Resting scapular posture in healthy overhead throwing athletes. Man Ther. 2013;18:547-50.

7. Jinzaki M, Yamada Y, Nagura T, Nakahara T, Yokoyama Y, Narita K, Ogihara $\mathrm{N}$, Yamada M. Development of upright computed tomography with area detector for whole-body scans: phantom study, efficacy on workflow, effect of gravity on human body, and potential clinical impact. Invest Radiol. 2020; 55:73-83.

8. Yamada Y, Yamada M, Yokoyama Y, Tanabe A, Matsuoka S, Niijima Y, Narita K, Nakahara T, Murata M, Fukunaga K, Chubachi S, Jinzaki M. Differences in lung and lobe volumes between supine and standing positions scanned with conventional and newly developed 320-detector-row upright CT: intraindividual comparison. Respiration. 2020;99:598-605.

9. Aebi M. The adult scoliosis. Eur Spine J. 2005;14:925-48

10. Wu G, van der Helm FC, Veeger HE, Makhsous M, Van Roy P, Anglin C, Nagels J, Karduna AR, McQuade K, Wang X, Werner FW, Buchholz B. International Society of B: ISB recommendation on definitions of joint coordinate systems of various joints for the reporting of human joint motion--part II: shoulder, elbow, wrist and hand. J Biomech. 2005;38:981-92.

11. Kibler WB. The role of the scapula in athletic shoulder function. Am J Sports Med. 1998;26:325-37.

12. Kibler WB, McMullen J. Scapular dyskinesis and its relation to shoulder pain. J Am Acad Orthop Surg. 2003;11:142-51.

13. Kibler WB, Sciascia A, Wilkes T. Scapular dyskinesis and its relation to shoulder injury. J Am Acad Orthop Surg. 2012;20:364-72.

14. Burkhart SS, Morgan CD, Kibler WB. The disabled throwing shoulder: spectrum of pathology Part III: The SICK scapula, scapular dyskinesis, the kinetic chain, and rehabilitation. Arthroscopy. 2003;19:641-61.

15. Gumina S, Carbone S, Postacchini F. Scapular dyskinesis and SICK scapula syndrome in patients with chronic type III acromioclavicular dislocation. Arthroscopy. 2009;25:40-5.

16. Plagenhoef $\mathrm{S}$, Evans FG, Abdelnour T. Anatomical data for analyzing human motion. Res Q Exerc Sport. 1983;54:169-78.

17. de Leva P. Adjustments to Zatsiorsky-Seluyanov's segment inertia parameters. J Biomech. 1996;29:1223-30.

18. Gustafsson A, Lindenfors P. Human size evolution: no evolutionary allometric relationship between male and female stature. J Hum Evol. 2004; 47:253-66.

19. Matsumura N, Oki S, Ogawa K, Iwamoto T, Ochi K, Sato K, Nagura T. Threedimensional anthropometric analysis of the glenohumeral joint in a normal Japanese population. J Shoulder Elbow Surg. 2016;25:493-501.

20. Bellemare $F$, Jeanneret $A$, Couture J. Sex differences in thoracic dimensions and configuration. Am J Respir Crit Care Med. 2003;168:305-12.
21. Haizlip KM, Harrison BC, Leinwand LA. Sex-based differences in skeletal muscle kinetics and fiber-type composition. Physiology (Bethesda). 2015;30: 30-9.

\section{Publisher's Note}

Springer Nature remains neutral with regard to jurisdictional claims in published maps and institutional affiliations.
Ready to submit your research? Choose BMC and benefit from:

- fast, convenient online submission

- thorough peer review by experienced researchers in your field

- rapid publication on acceptance

- support for research data, including large and complex data types

- gold Open Access which fosters wider collaboration and increased citations

- maximum visibility for your research: over $100 \mathrm{M}$ website views per year

At BMC, research is always in progress.

Learn more biomedcentral.com/submissions 